\title{
CYSTINOSIS: A RARE CASE PRESENTATION
}

\author{
Karan Hantodkar ${ }^{1}$, Mahesh Mohite ${ }^{2}$, Pankaj Deshpande ${ }^{3}$ \\ ${ }^{1}$ Senior Resident, Sai Child Care Clinic and Pediatric Multispecialty Hospital, New Panvel, Navi Mumbai, Maharashtra, India \\ ${ }^{2}$ Director of Sai Child Care Clinic and Pediatric Multispecialty Hospital,Wadia Children Hospital Mumbai, Maharashtra, India \\ ${ }^{3}$ Pediatric Nephrologist PD Hinduja Hospital, Sai Child Care Clinic, Mumbai, Maharashtra, India
}

Conflict of Interest - NIL, Received - 23/07/2015, Accepted - 12/08/2015, Published 13/08/2015

ABSTRACT - Cystinosis is a systemic disease caused by defect in metabolism of Cystine. It typically presents as Fanconi syndrome with metabolic acidosis, polyuria, failure to thrive, glucosuria, phophaturia and aminoaciduria. Our patient did not display metabolic acidosis at presentation and had features suggesting Bartter's syndrome.

KEYWORDS - Cystinosis, Metabolic Acidosis, Bartter's Syndrome

\section{INTRODUCTION}

Cystinosis is a systemic disease caused by defect in metabolism of Cystine. It typicallypresents as Fanconi syndrome with metabolic acidosis, polyuria, failure to thrive, glucosuria,phophaturia and aminoaciduria. Our patient did not display metabolic acidosis at presentation and hadfeatures suggesting Bartter's syndrome.

\section{CASE PRESENTATION}

A 2 year girl presented with history of failure to thrive and polyuria since 9 month of age. She had grown well prior to that. She was born at term, normal vaginal delivery, birth weight $2.7 \mathrm{~kg}$, length $47 \mathrm{~cm}$ and head circumference $34 \mathrm{~cm}$. Her initial physical milestones were normal but she never walked and language was appropriate for age. Presenting at 2 years of age her weight was $5.9 \mathrm{~kg}$, height $68 \mathrm{~cm}$ and head circumference $44 \mathrm{~cm}$. Blood pressures was normal. She had severe polyuria (urine output more than $6 \mathrm{ml} / \mathrm{kg} / \mathrm{hr}$ ). Venous blood gas showed a $\mathrm{pH}$ of 7.48 with the $\mathrm{HCO} 3$ value of

20. She had hyponatremia (serum sodium 126 $\mathrm{mEq} / \mathrm{L}$ ), severe hypokalemia (serum potassium 1.0 $\mathrm{mEq} / \mathrm{L}$ ) and hypochloremia (serum chloride 84
$\mathrm{mEq} / \mathrm{L}$ ).Hypercalciuria (urine calcium: creatinine 0.6) was also noted. Serum creatinine was normal $(0.4 \mathrm{mg} / \mathrm{dL})$.

She also had a low serum phosphorus $(2.9 \mathrm{mg} / \mathrm{dl})$ and calcium $(7.4 \mathrm{mg} / \mathrm{dl})$ with mild elevation of alkaline phosphatase (307IU/lit). The $25 \mathrm{OH}$ Vit D levels were high. The urine electrolytes showed a high urine chloride $(39 \mathrm{mmol} / \mathrm{lit})$. The combination of hypokalemia, hypochloremia, no metabolic acidosis and a high urinary chloride was suggestive of Bartter's syndrome. However the hypophosphatemia was not in concurrence. Hence other possibilities were kept in mind and investigations including an ophthalmic examination recommended though therapy was commenced for Bartter's syndrome.

There was irregular follow-up and the ophthalmic examination was not done early. 6 months later she presented with severe metabolic acidosis along with severe hyponatremia (107meq/lit), hypokalemia $(2.1 \mathrm{meq} / \mathrm{lit})$ and hypochloremia (72meq/lit). The hypophosphatemia (2.6mg/dl) persisted and investigations also revealed aminoaciduria. Ophthalmic evaluation was done (C) International Journal of Recent of Surgical and Medical Science | Jul-Dec 2015 | Vol 1 | Issue $1 \mid$ (C) Society for Medicine \& Surgical Update (SMSU) www.ijrsms.com 
which revealed Cystine deposits in cornea on slit lamp examination. This confirmed a diagnosis of cystinosis.

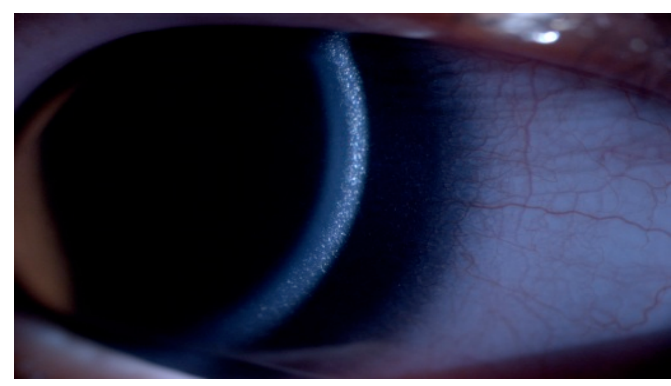

Figure 1(a) - Cystine Crystals in Cornea on Slit lamp examination

\section{DISCUSSION}

Cystinosis is an autosomal recessive lysosomal storage disorder caused by defective transport of amino acid cystine out of lysosome (1). This stored cystine is poorly soluble and crystallizes within lysosome of many cell types leading to widespread tissue and organ damage. It has 3 variants (Infantile onset, late onset and ophthalmic). Children with Infantile cystinosis present early, usually in the first year of life with failure to thrive and polyuria, metabolic acidosis, hypokalemia and features of Fanconi syndrome (2). Severe hypophosphatemia is the hallmark due to tubular loss of phosphorus (3).

This child presented with polyuria, polydipsia, and failure to thrive but had hypokalemia, hypochloremia with a raised urinary chloride and no evidence of metabolic acidosis. These are classical features of Bartter's syndrome $(4,5)$. However, Bartter's syndrome usually does not show a low phosphorus level and if they do develop nutritional rickets, they will show low levels of Vitamin D. This girl had low phosphorus with normal/high levels of Vitamin D. hence there was a suspicion that this was not so straightforward The confirmatory test for cystinosis is ophthalmic evaluation which classically demonstrates the cysteine crystals in the cornea. The girl had evidence of this and she eventually did present with severe metabolic acidosis and all features of Fanconi syndrome. This is an extremely rare presentation of Cystinosis but has been described earlier (6-8). As to the reason why this type of presentation occurs is not completely understood but there are theories. One of the theories is that before cysteine accumulates in sufficient quantities in the lysosomes to cause the typical Fanconi syndrome, the accumulation probably damages the sodium-potassium ATPase in the tubular cell lining thereby causing a leak of all these electrolytes simulating Bartter's syndrome (9). Eventually as the cysteine accumulation progresses, the typical clinical picture emerges (10-13).

Treatment consists of Soda mint to correct acidosis, potassium supplements, phosphate supplements like Joulie's solution and good nutrition. Specific therapy is with cysteamine that helps cysteine to egress the cell (14). However it is a dreadful illness with a poor prognosis. Untreated, children will go into end stage renal disease by adolescence. Even with cysteamin treatment which is very intensive, they will eventually reach ESRD by 25 to 30 years of age (15). It also affects other organs like the pancreas, thyroid etc causing hypothyroidism, diabetes mellitus etc. Hence even after a renal transplant, cysteamine treatment is usually required lifelong. Cysteamine drops for the eyes are also used to reduce deposits in the cornea.

\section{CONCLUSION}

Cystinosis is a dreadful illness with a uniformly poor prognosis in terms of renal function. On the other hand, Bartter's syndrome has many electrolyte abnormalities but most children will do well in the long term. Hence it is extremely important to be aware of this masquerading nature 
of Cystinosis with regards to Bartters syndrome so that the diagnosis is not missed.

\section{REFERENCES}

1. Kalatzis V, Antignac C. New aspects of the pathogenesis of cystinosis. Pediatric Nephrol. 2003;18:207-15. [PubMed]

2. Nesterova G, Gahl W. Nephropathic cystinosis: late complications of a multisystemic disease. Pediatr Nephrol. 2008;23(6):863-78. Review.[PubMed]

3. Baroncelli GI, Bertelloni S, Sodini F, et al. Genetic advances, biochemical and clinical features and critical approach to treatment of patients with X-linked hypophosphatemic rickets. Pediatr Endocrinol Rev. 2004;4:361-79. [PubMed]

4. Berio A. Nephropathy caused by cystinosis with secondary Bartter's syndrome. Personal experience in a case treated with prolonged diet therapy and acetylsalicylic acid therapy. Minerva Pediatr. 1978;30:1825-31. [PubMed]

5. Lemire J, Kaplan BS. The various renal manifestations of the form of cystinosis. Am J Nephrol. 1984;4:81-5. [PubMed]

6. A patient with cystinosis presenting like Bartter syndrome and review ofliterature.Ertan $\mathrm{P}$, Evrengal $\mathrm{H}$, Ozen $\mathrm{S}$, Emre S. Iran J Pediatr. 2012 22(4):543-546

7. Cystinosis presenting with findings of Bartter's syndrome. Ozka. B, Cayir A, Kosan C, Ao H. J Clin RES PediatrEndocrinolo 2011, 3(2):101-104
8. Rare presentation of cystinosis mimicking bartter's syndrome: reports of two patients and review of literature. Caltik A, Akynz SG, Erdogan O, Bubul M, Demircin G. Renal failure, 2010, 32(2):277-280

9. Coor C, Salmon RF, Quigley R, et al. Role of adenosine triphosphate (ATP) and NaK ATPase in the inhibition of proximal tubule transport with intracellular cystine loading. J Clin Invest. 1991;87(3):955-61. [PMC free article] [PubMed]

10. O'Regan S, Mongeau JG, Robitaile P. A patient with cystinosis presenting with the features of Bartter syndrome. Acta Pediatr Belg. 1980;44:638-46.

11. Whyte MP, Shaheb S, Schanaper HW. Cystinosis presenting with features suggesting Bartter syndrome. Case report and Literature review. Clin Pediatr (Phila) 1985;24:447-51. [PubMed]

12. Yildiz B, Durmus-Aydogdu S, Kural N, et al. A patient with cystinosis presenting transient features of Bartter syndrome. Turk J Pediatr.2006;48:260-2. [PubMed]

13. Caltik A, Akyüz SG, Erdogan O, et al. Rare presentation of cystinosis mimicking Bartter's syndrome: reports of two patients and review of the literature. Ren Fail. 2010;32(2):277-80. Review. [PubMed]

14. Gahl WA, Thoene JG, Schneider JA. Cystinosis. N Engl J Med. 2002;347:111-21. [PubMed]

15. Pennesi M, Marchetti F, Crovella S, et al. A new mutation in two siblings with cystinosis presenting with Bartter syndrome. PediatrNephrol.2005;20:2179.[PubMed]

How to cite this article - Hantodkar $\mathrm{K}$, Mohite $\mathrm{M}$, Deshpande $\mathrm{P}$, A rare presentation of Cystinosis, IJRSMS, 2015;01(1): 2-4 